\title{
Perfis: modos de inserção de jornais televisivos
}

Mayra Rodrigues Gomes

Professora doutora, livre-docente, do Departamento de Jornalismo

e Editoração da ECA/USP.

E-mail: mayra@sdev.com

Uma longa pesquisa, cujos primeiros passos foram ensaiados em 1999, conduz, em uma de suas etapas, às considerações que serão expostas neste texto. Fases anteriores já se encontram publicadas, inclusive a apresentada como tese de livre-docência em 2003¹.

Trabalhamos com conceitos centrais ao pensamento de Michel Foucault, aplicando-os à produção jornalística. Tais conceitos fazem eco à noção de sociedades disciplinares, isto é, sociedades em que se substitui o princípio da soberania pelo da disciplina que se baseia na formação pela educação, visando à inserção funcional dos indivíduos nos modos de vida relacionados a regimes de produção. As sociedades disciplinares são características das organizações sociais e políticas na modernidade, e relacionam-se ao fato de que essas organizações só podem encontrar efetividade com uma tática de quadriculamento do espaço, tanto físico quanto gnosiológico. "A disciplina é, antes de tudo, a análise do espaço. É a individualização pelo espaço, a inserção dos corpos em um espaço individualizado, classificatório, combinatório"2.

O que se obtém com a individuação e a classificação é um campo definido, com procedimentos que lhe são próprios e, assim, ditos corretos. Por exemplo, dentro de uma universidade há partições bem definidas: o campo dos alunos, dos professores, dos funcionários administrativos, todos vivendo uma hierarquia com funções e prerrogativas específicas. A individuação, ou delineamento dos espaços, oferece uma dimensão propícia à instalação e ao exercício de dispositivos disciplinares, ou seja, de procedimentos que veicularão a norma e seu reforço. Os quadrículos, ou espaços desenhados por essa divisão espacial, física ou virtual, são, eles próprios, elementos disciplinadores enquanto organizam o campo do que deve ser visto, do que deve ser objeto de nossa atenção.

\section{O QUADRICULADO DO JORNALISMO}

Assim, foi nossa hipótese de pesquisa, e agora é nosso pressuposto, que a produção jornalística opera em correspondência ao princípio de organização do espaço gnosiológico. Constitui, isolando e classificando partes, um espaço público. Para que pudéssemos recuperar o desenho do quadriculado deste espaço, tomamos como vetores as práticas de vigilância e denúncia, historicamente

1. GOMES, Mayra Rodrigues. Jornalismo e filosofia da comunicação. São Paulo: Escrituras, 2004.

2. FOUCAULT, Michel. Microfísica do poder. Rio de Janeiro: Graal, 2001. p. 106. 
vinculadas ao trabalho jornalístico. Tal quadriculado se mostrou na forma de tópicos reincidentes aos quais podemos subsumir as matérias jornalísticas, apesar de suas inúmeras variações em função de um devir factual.

Obtivemos um conjunto de quadrículos que se compõem, ou compõem os seguintes tópicos: Acidentes/Catástrofes, Atos de Guerra, Atos de Governo, Atos ou Manifestações pelos Direitos Humanos, Auto-referencialidade, Criminalidade/Violência, Economia, Esportes, Estatísticas e Reportagens sobre BemEstar, Modos de Vida, Notícias sobre Eventos ligados à Cultura, à Ciência e a Personalidades de Destaque, Opiniões sobre Projetos e Efeitos, Política.

A partir de coletas realizadas junto aos veículos Jornal Nacional, Jornal da Record e Jornal da Cultura, que tomamos como objetos de teste, durante 2002, 2003 e 2004, tivemos a confirmação do quadriculado e seus quadrículos. Estes são sustentáveis porque se mantêm no decorrer do tempo e subsumem as variações nos acontecimentos.

Supúnhamos em nossos estudos a incidência constante dos tópicos que formam os quadrículos, como o trabalho de quadriculamento do espaço, necessário à instalação de dispositivos disciplinares que começam por constituir os próprios quadrículos e evoluem para o que se coloca como pertinente a cada um deles.

\section{DE UM QUADRICULADO A PALAVRAS DE ORDEM}

Supúnhamos, também, a existência de quadrículos como topoi, isto é, lugares lógicos, necessários ao exercício do que Gilles Deleuze nos aponta em termos de palavra de ordem, consistência de toda comunicação:

Os jornais, as notícias, procedem por redundância, pelo fato de nos dizerem o que é "necessário" pensar, reter, esperar etc. A linguagem não é informativa nem comunicativa, não é comunicação de informação, mas - o que é bastante diferente

- transmissão de palavras de ordem, seja de um enunciado a um outro, seja no interior de cada enunciado, uma vez que o enunciado realiza um ato e que o ato se realiza no enunciado"3.

Por palavra de ordem, como função primeira da linguagem, entende-se que toda fala é sempre indutiva de modos de vida, é sempre uma ordem, ainda que não venha construída com verbos no imperativo. Basta tomarmos qualquer simples observação para constatarmos este fato, mas, talvez, um exemplo perfeito seja a notação da mãe que diz ao filho: "Está frio lá fora!". Sabemos, embora o filho nem sempre o saiba, que essa descrição do clima é, na verdade, um comando sobre os modos a serem adotados, nesse caso sobre um tipo de vestimenta considerada adequada. Nesses termos, um quadrículo já é palavra de ordem, pois organiza o que deve ser olhado e permite que os modos de olhar, ou agir, sejam apresentados e reforçados a partir da individuação e classificação efetuadas. Nossos estudos estiveram a serviço da demonstração dessas operações pelas quais se realizam os dispositivos disciplinares e as palavras de ordem.

Contudo, se os quadrículos servem a toda forma de distribuição das palavras de ordem, temos uma última tarefa, a saber, a de examinar os jornais televisivos 
estudados sob a ótica de sua inserção no quadriculado. Resta-nos aplicar os princípios de vigilância e denúncia aos próprios veículos, para que possamos vê-los em suas formas particulares de operação, internamente a cada quadrículo.

\section{O JORNALISMO NO QUADRICULADO}

Começamos por explorar a possibilidade de contestação dos espaços constituídos, primeiro ponto sobre o qual vigilância e denúncia podem ser examinadas. Nesse caso, a confirmação realizada pelos três veículos nos fala de aceitação pela adoção constante dos mesmos tópicos e da mesma organização. Vários autores assinalaram anteriormente esta condição. Pierre Bourdieu, por exemplo, pronunciou-se em termos de uma posição hegemônica do jornalismo quanto ao formato e ao conteúdo de sua exposição:

Nada tenho, evidentemente, contra a concorrência, mas observo apenas que, quando ela se exerce entre jornalistas ou jornais que estão sujeitos às mesmas restrições, às mesmas pesquisas de opinião, aos mesmos anunciantes (basta ver com que facilidade os jornalistas passam de um jornal a outro), ela homogeneíza ${ }^{4}$.

Em relação a essa prática fica evidente o papel da repetição como operação genética, isto é, como gênese e suporte da comunicação, operação que Deleuze relacionava à procura de efeito de aplainamento das diferenças. Fica notória, também, uma vigilância implícita sobre os modos de ver e organizar a vida social. Dessa forma, o quadriculado jamais é contestado e opera como chão para o exercício do jornalismo.

A alternativa diferenciada que nos resta examinar, quanto à assunção deste quadro hegemônico, restringe-se então à freqüência temática estabelecida em cada veículo. Por confronto, num universo de matérias que somam, respectivamente, 135 no Jornal Nacional, 117 no Jornal da Record, 108 no Jornal da Cultura, obtivemos uma distribuição que ilustra as incidências em nossa coleta referente à primeira semana de março de 2004 (veja gráfico a seguir).

Ante este quadro, impõe-se o exame das discrepâncias nítidas, que podem delinear os perfis dos jornais, e das coincidências notórias, as quais podem oferecer a oportunidade de observar modos diferenciados de inserção, de cada veículo, em relação aos tópicos.

Nas discrepâncias, ressalta-se a baixa incidência de notícias sobre eventos culturais no Jornal da Record em oposição à alta incidência delas no Jornal da Cultura. Como o nome da rede anuncia, uma de suas características é um foco direcionado a eventos artísticos e culturais de modo geral. Esse dado, somado à menor incidência no tópico Esportes, desenha o perfil do jornal e, ao mesmo tempo, seu modo de localização no quadriculado. A primazia dada à cultura certamente desloca o foco da concentração em Atos de Governo, afirmada pelos três veículos e sobre a qual falaremos logo mais. Esse viés marca a inserção do Jornal da Cultura como veículo que pretende abarcar, com suas matérias, a vida como um todo, preservando um lugar para a individualidade e as manifestações

4. BOURDIEU, Pierre. Sobre a televisão: a influência do jornalismo. Rio de Janeiro: Jorge Zahar, 1997. p. 31. 


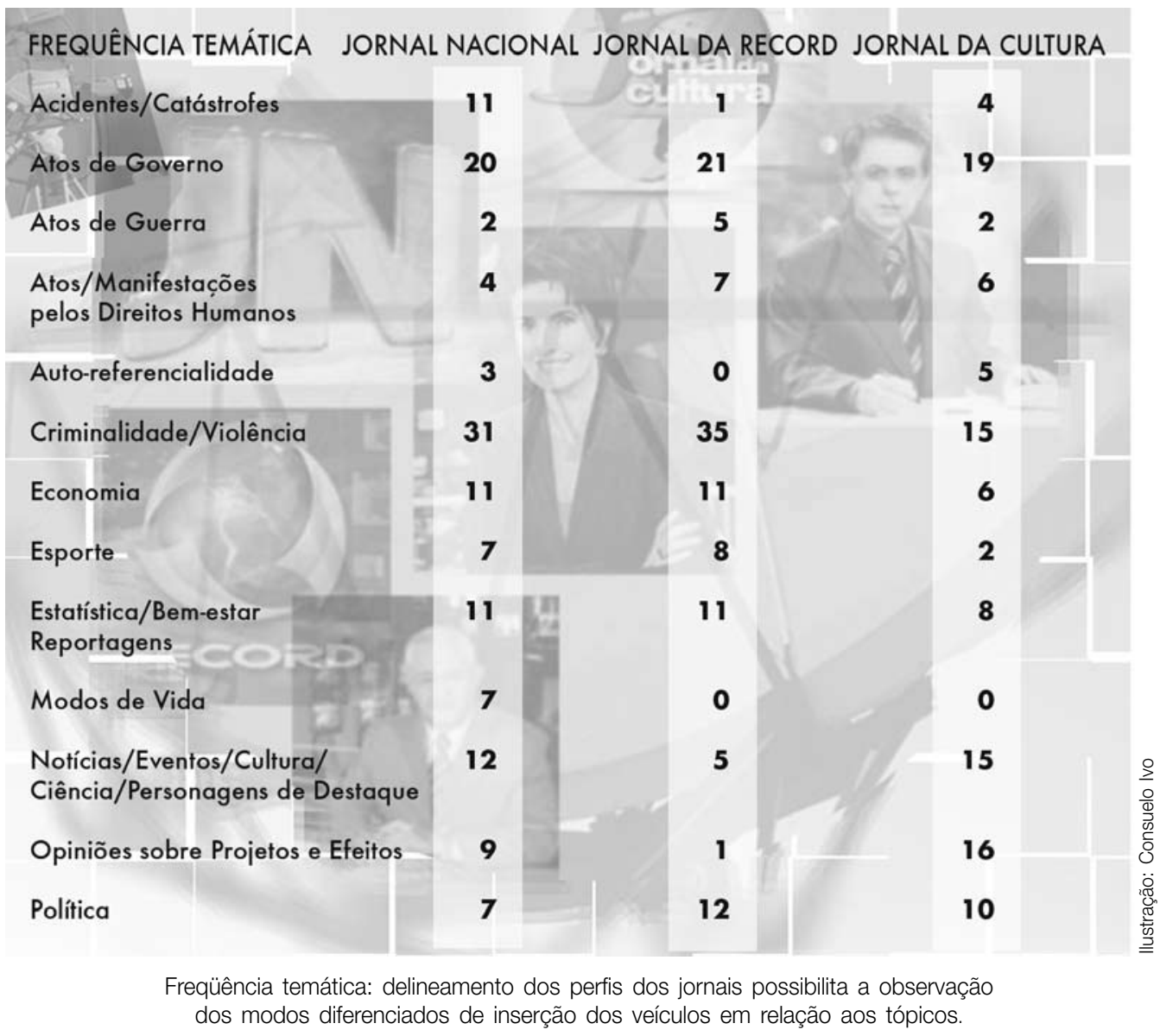

únicas, como as artísticas. Marca o componente humanístico, numa cobrança por qualidade de vida que não se equacione pela lógica do bem-estar social, pois leva em conta qualidade de vida enquanto fruição.

Por outro lado, a não-manifestação do Jornal da Record sobre este tópico, assim como sobre o tópico Modos de Vida, também traça a tomada de posição no quadriculado, a saber, a de um veículo que volta seu olhar prioritariamente sobre o poder constituído, o qual se coloca a distância da distração e das formas lúdicas e também das excentricidades. Soma-se a isto uma maior incidência, em relação aos outros jornais, quanto ao tópico Criminalidade/Violência, fato que, per se, indica atenção às desordens no plano social como um todo. Condizente com essa postura, sua inserção no quadriculado se pauta pela vigilância sobre o poder, tendo como pano de fundo a ordem instituída, implicitamente reafirmando-a. Ainda de modo condizente, lembra e cobra deveres ao Estado, aos políticos e a todos os cidadãos em alguma posição de poder.

Outro descompasso, entre incidências, pode ser identificado pelo número de matérias dedicadas ao tópico Acidentes/Catástrofes. Em comparação aos outros dois veículos, o Jornal Nacional apresenta alto número de reportagens dedicadas a ele. Claro que essa ocorrência também é índice do modo de colocação do jornal no quadriculado, neste caso na forma da prioridade àquilo que foge de padrões e de expectativas, causando surpresa e prendendo a atenção. Não 
queremos associar esse procedimento àquele normalmente vinculado à imprensa sensacionalista, pois nela a postura de excesso é marcante, enquanto o Jornal Nacional esforça-se por ser comedido, sem exageros na narrativa dos fatos. A ênfase dada resume-se ao número de incidências e não ao tratamento. Entretanto, o veículo coloca-se no ponto um tanto delicado em que, procurando informar, se norteia pela captação de audiência na forma explícita da sedução.

Um outro critério pode confirmar essas observações. Trata-se da posição das notícias na seqüência das matérias. O tópico Acidentes/Catástrofes é constantemente inserido no primeiro bloco, tanto pelo Jornal Nacional quanto pelo Jornal da Record, enquanto no Jornal da Cultura não há padrão de localização para este tópico.

\section{DA AUTO-REFERENCIALIDADE}

Outro diferencial pode ser observado, nesta coleta, em relação ao tópico Auto-referencialidade. Este merece um capítulo à parte, pois como ele é o próprio jornal que se assume como enunciador, ao fazê-lo, diz o que pretende ser em relação aos procedimentos de vigilância e denúncia.

Tendo em mente que os tópicos são determinados pelo tema central da matéria, podemos relativizar a contagem final de incidências. Para o Jornal da Record, a ausência de manifestação, nesse período, sobre o tópico Auto-referencialidade deve ser desconsiderada, uma vez que a referência a si próprio aparece de forma secundária, não só no conjunto das matérias, mas também nas formulações dos âncoras. Como demonstração deste fato, apontamos a edição de $1^{\circ}$ de março de 2003, na qual, em matéria sobre Atos de Governo, Boris Casoy lembra que o processo por danos morais movido contra a Rede Record pelo ex-senador Luiz Estevão, em virtude de comentários feitos pelo âncora do Jornal da Record, a saber, ele mesmo, foi considerado improcedente. O mesmo ocorre em relação à baixa incidência na temática Opiniões sobre Projetos e Efeitos, uma vez que Boris Casoy pontifica sobre todas as questões, às vezes acrescentando um "Isto é uma vergonha".

Ora, temos aí o modo como o jornal diz que atua, a saber, pela crítica ou denúncia das ocorrências que ferem dispositivos da ordem social. O compromisso do jornal vem a ser, em suas próprias palavras, o da vigilância que cobra, reclama e conclama a manutenção da ordem. Nossas coletas precedentes nos autorizam esta afirmação e a elas recorremos como exemplificação.

Em 14 de junho de 2002, o Jornal da Record anuncia:

Programa Passando a Limpo. No próximo domingo vou entrevistar o candidato do PT à presidência, Luiz Inácio Lula da Silva. Vou receber também o presidente da Associação Brasileira de Agrobusiness, Roberto Rodrigues. Passando a Limpo vai ao ar no domingo, às $11 \mathrm{~h} 30$ aqui na Rede Record.

Em 19 de março de 2003, repete o procedimento:

No programa Passando a Limpo do próximo domingo vou entrevistar o governador do Espírito Santo, Paulo Hartung, do PSB. Vou receber também o Secretário da Administração Penitenciária de São Paulo, Nagashi Furokawa. O programa Passando a Limpo vai ao ar domingo, às $11 \mathrm{~h} 30$ da noite, aqui na Rede Record. 
A auto-referencialidade, ao mesmo tempo ao âncora e à rede televisiva, marca o olhar atento às instituições públicas, a procura de explicações por meio das entrevistas, enfim, a cobrança sustentável porque sustentada pela informação pormenorizada.

O Jornal Nacional, em 2 de março de 2004, corrige afirmações feitas no dia anterior, ressalvando que a recuperação de rodovias é parceria de produtores com o governo mato-grossense e não com o governo federal, como havia dito então. Fica assim assentado o compromisso com os fatos e uma cobrança da ordem por parte do jornal sobre si mesmo. O mesmo empenho é manifesto na manutenção de correspondentes no exterior, como é o caso de Caco Barcellos, anunciado, em março de 2004, como novo correspondente do jornal em Paris.

O empenho com a informação é reivindicado pelos três veículos, mas no Jornal Nacional tem uma conotação específica, pois se volta a um projeto que poderíamos chamar iluminista, no sentido de indução a um aprimoramento dos modos de vida. A informação passada pelas reportagens, relacionada a outros programas da emissora, sempre surge com o viés da educação para uma vida melhor.

É assim que, em 5 de março de 2004, se anuncia: "O Globo Repórter de hoje fala sobre como a rotina diária pode ser transformada em vida saudável”. Somos então confrontados com uma prévia de recomendações sobre posturas corporais e hábitos alimentares.

Em 25 de maio de 2002, o veículo se insere explicitamente no trabalho de educação como emancipação por meio da auto-referencialidade a seus feitos. Nesse dia, o Jornal Nacional menciona que a novela $O$ Clone recebeu homenagem especial da Academia de Medicina pela sua campanha contra as drogas. Declara, então, que a Rede Globo vem realizando merchandising social há várias décadas, com programas voltados a iniciativas de interesse da sociedade, sem fins comerciais. A emissora já ganhou prêmios por essa iniciativa no passado, pela colocação da realidade em meio à ficção. Exemplos: em 1997, a novela A Indomada alertava para a exploração do trabalho infantil, o que gerou no Paraná blitz para averiguação; em $O$ Espigão, de 1974, e $O$ Rei do Gado, de 1996, foi central a preocupação com o meio ambiente; o alcoolismo e a ajuda dada pela irmandade Alcoólatras Anônimos também foram abordados, assim como a Aids, em O Portador (1991) e Zazá (1997); a doação de sangue, o parto normal e o aleitamento materno receberam incentivos em Por Amor (1997); Explode Coração (1995), ao retratar o movimento de mães à procura de filhos desaparecidos, incitou o encontro, por suas famílias, de 70 crianças; a luta contra o câncer e a doação de medula, que aumentou depois de sua exibição, foram temas de Laços de Família (2000); já Torre de Babel, de 1998, mostrou a luta do dependente químico e $O$ Clone (2001) usou depoimentos de dependentes e ex-dependentes de droga.

Em março de 2003, durante toda uma semana, o Jornal Nacional reportase a si próprio por conta da Série sobre o Petróleo, que apresentou de segunda a sábado. A série, embora faça um apanhado histórico das origens, das disputas 
e da industrialização, não deixa passar a oportunidade de ressaltar as aplicações do petróleo no Brasil, as jazidas marinhas, os benefícios que estas trouxeram a comunidades vizinhas e os auferidos em nossa vida diária.

No Jornal da Cultura, em $1^{\circ}$ de março de 2004, há diversos anúncios que, embora não sejam feitos no ambiente dos ganchos, têm este valor e apontam para o papel da presença do jornal diante dos fatos, para seu compromisso com o espectador, porque, afinal, o programa retornará fazendo o percurso total da informação. É o caso dos dizeres:

Daqui a pouquinho você vai ver como o diretor do FMI defendeu a política econômica do governo Lula;

Ainda nesta edição você vai acompanhar a previsão do tempo para São Paulo;

Mais sobre a noite de entrega do Oscar ainda hoje, nesta edição;

Na semana passada, mostramos aqui que se questiona o fechamento dos bingos por causa de desemprego. Hoje a Força Sindical organizou manifestação em São Paulo.

Há, portanto, uma preocupação com a continuidade, não só a do próprio programa, foco dos ganchos, mas também a da informação. Esse mergulho que o jornal pretende realizar é colocado em termos de expansão do saber, e o jornal se posta a serviço deste ideal assim como a serviço do espectador. É o que ocorre em 4 de março de 2004, quando Celso Zucatelli anuncia: "Você tem visto muitas reportagens sobre poder judiciário porque é necessário saber como funciona. Se quiser saber mais alguma coisa é só escrever para nosso e-mail'.

Acresce-se uma justificativa, do próprio jornal, quanto ao baixo índice de incidências sobre a temática Criminalidade/Violência. Em 2 de março de 2004, na matéria sobre os ataques xiitas que deixaram 170 mortos no Iraque, matéria que, portanto, não se inscreve como auto-referencial, Celso Zucatelli, apontando um monitor de computador, afirma que imagens de violência chegam pela internet a todo instante, mas que o Jornal da Cultura não vai mostrá-las. Fica explícita assim uma posição do jornal de não-uso de imagens de impacto, as que atraem audiência, em prol do compromisso com a transparência na informação.

Em 20 de junho de 2002, anuncia-se: "Daqui a pouco o Conversa Afiada, com Paulo Henrique Amorim, falará sobre a situação econômica”. Em 24 de março de 2003, Cunha Junior anuncia: "shows no Centro Cultural do Rio, o disco novo do Sepultura e maiores informações sobre o Oscar logo mais no seu programa Metrópolis, que vai ao ar às 10 horas". Tanto num caso como no outro, temos um projeto de continuidade, de uma informação expandida em que esta se coloca a serviço de si própria, sem outros álibis. Mas, o que é mais importante, delineia-se um olhar, ausente nos outros dois jornais, voltado para eventos culturais, interna e externamente ao programa, que dá o perfil não só do programa, porém, talvez, da própria rede televisiva.

Outra instância a ser considerada, no traçado de um perfil dos veículos, é o tom em que uma notícia sobre trâmites econômicos é transmitida. Em 3 de março de 2004 anuncia-se a fusão da Ambev com a Interbrew, com o nome provisório de Interbrev. O Jornal Nacional opta por frisar o resultado da operação 
como o surgimento da maior cervejaria do mundo, na qual o Brasil teria uma participação ativa. Não são mencionados os pormenores da transação. Firmase a impressão de um quadro positivo, de crescimento econômico em que o Brasil tem papel relevante.

Enquanto isso, o Jornal da Cultura explorou a questão de forma a mostrar uma megaoperação que permite a sobrevivência de várias cervejarias e o Jornal da Record mostrou que a parcela de autonomia brasileira nesta fusão permanecerá inferior. Vê-se que no Jornal Nacional é constante o desenho de um quadro favorável ao Brasil, em que a economia, e as decisões governamentais a ela relacionadas, trabalha pela ordem ideal, em que o país se encaminha a destinos respeitáveis: um ufanismo leve é constantemente delineado.

\section{FORMAS DISCREPANTES}

Exploramos a freqüência da incidência temática em suas formas discrepantes. Resta-nos uma atenção às confluências. Desde o início desta pesquisa, que, como dissemos, percorre emissões de 2002, 2003 e 2004, e corresponde a uma coleta (gravação em vídeo) de edições do Jornal Nacional, do Jornal da Record e do Jornal da Cultura, constatamos um foco hegemônico, a saber, a alta incidência de matérias sob o tópico, ou quadrículo, Atos de Governo.

Este dado representou, para nossos estudos, a confirmação dos processos de vigilância e denúncia em prol do poder constituído, de forma a permitir constante emissão de palavras de ordem pela própria ordem instituída.

Neste momento em que procuramos mostrar os modos de inserção dos veículos nos quadrículos por eles mesmos dispostos, essa confluência torna-se ponto privilegiado em que podemos identificar tais modos, as formas de abordagem ante um mesmo tema. Um eixo que nos pode auxiliar nesta tarefa é a observação das fontes, porque seu número se relaciona tanto à meta de apuração dos fatos quanto à meta de diversidade de opiniões, elementos do ideário jornalístico e do direito à informação postulado pela luta por direitos humanos. Tomaremos um caso modelo, dentre aqueles sob o tópico Atos de Governo, no conjunto de nossa última coleta que corresponde à primeira semana de março de 2004.

Relembrando, essa semana é precedida pela eclosão do escândalo Waldo-

5. Em 2004, a acusação de que um dos principais homens de confiança do então ministro José Dirceu (Casa Civil) negociava com bicheiros o favorecimento em concorrências, em troca de propinas e contribuições para campanhas eleitorais, iniciou a maior crise no governo de Luiz Inácio Lula da Silva. [N.E.] miro Diniz, a qual toma conta dos noticiários em geral e, portanto, se inscreve como caso privilegiado.

Do ponto de vista da representatividade temática, Atos do Governo, que compreende matérias referentes a todas as ações empreendidas pelo governo, encerra as manifestações sobre o caso Waldomiro Diniz ${ }^{5}$. A contagem equilibrada da incidência apresentada pelos três veículos, respectivamente, 20, 21 e 19, não nos revela nada a não ser a preponderância das medidas de ordem e de vigilância sobre o campo social (atribuições governamentais), medidas que o jornalismo reforça em sua vigília sobre a ordem instituída, foco central do jornalismo e foco originário de nossa pesquisa. 
Por isso a escolha de um caso modelo é necessária e nos leva ao isolamento, dentre as matérias, daquelas voltadas para o caso em questão. Embora muitas delas se cruzem de forma indireta, levaremos em conta somente as explicitamente delineadas na perspectiva de tal evento. É aí que notamos a primeira distinção de posições.

Dentre as 20 matérias que o Jornal Nacional dedica ao governo, 10 estão relacionadas ao caso Waldomiro, 2 são transmitidas no quinto bloco de notícias, 4 no quarto, 2 no terceiro e 2 no primeiro bloco. Notemos que o caso está em primeiro plano somente na terça-feira. Das 21 matérias que o Jornal da Record veiculou sobre o governo, 15 estão diretamente relacionadas ao caso, 10 no segundo bloco, 4 no primeiro bloco do dia $1^{\circ}$ de março e 1 no terceiro do mesmo dia. Dentre as 19 matérias que o Jornal da Cultura reservou ao tema, 14 relacionam-se ao caso Waldomiro, 1 no quinto bloco, 1 no terceiro, 2 no segundo e 10 distribuídas pelos primeiros blocos de todos os dias da semana.

Certamente esse quadro denota a atenção dedicada ao caso pelo Jornal da Cultura, dando-nos a certeza de que os eventos foram bastante esmiuçados, circunstância que nos deixa com a possibilidade de uma profundidade maior, pela exposição de diversos ângulos da questão.

Gostaríamos de ressaltar o fato, nada desprezível, de que, enquanto os outros dois veículos se voltavam para a cobertura dos eventos relacionados ao caso Waldomiro, o Jornal Nacional procurou concentrar suas matérias, em relação ao tópico Atos do Governo, nas propostas governamentais ligadas ao incentivo à construção civil e à dotação de verba para a recuperação de rodovias e ferrovias. Quanto a este último assunto, até desenvolveu uma extensa reportagem sobre a importância das vias de comunicação para o escoamento e exportação dos diversificados produtos brasileiros. Esta ocorrência chega a causar estranhamento, diante dos rumos seguidos pelos outros veículos, e passa a representar uma tentativa de desvio da atenção.

Em contrapartida, o Jornal da Cultura trouxe uma reportagem, com direito a depoimento de várias personagens implicadas, sobre a origem da fita incriminadora que foi parar na redação da revista Época. A narração dos fatos coube ao repórter Andrei Meirelles, que encabeçou a matéria da Época. Segundo ele, o senador Antero Paes de Barros, relator da CPI dos bancos dos Estados, costuma receber denúncias. A fita foi parar em suas mãos e ele não reconheceu as pessoas envolvidas. Acostumado a passar informações para o repórter Andrei Meirelles, entregou-lhe a fita dizendo que parecia haver corrupção ali, mas não sabia de que teor. $\mathrm{O}$ repórter identificou as pessoas e levou a fita a um perito da Unicamp para averiguar sua autenticidade. Somente três dias depois o senador foi informado de que Waldomiro Diniz tentava acordos com o bicheiro Carlinhos Cachoeira. Só esta reportagem envolveu o testemunho e a opinião de diversas pessoas, inclusive a dos âncoras do Jornal da Cultura, o que indica uma abertura para livre expressão que arrolamos como diversidade de fontes.

Quanto às fontes, na forma da presença de vozes diferenciadas, podemos explorá-las sob diferentes ângulos. Primeiramente consideraremos o quadro 
de incidências que apresentamos em relação ao tópico Opiniões sobre Projetos $e$ Efeitos. Este abarca as matérias voltadas para entrevistas, por elas constituídas, e em que a opinião de alguém é claramente buscada.

O Jornal Nacional, de um total de 130 matérias, dedica 9, de maneira exclusiva, a entrevistas; o Jornal da Record, de um total de 117, realiza, com exclusividade, somente uma; o Jornal da Cultura, num conjunto de 108, faz 16 e, portanto, supera os outros em incidência. Estes dados dizem respeito a nossa coleta (corpus) de 2004. Ainda que a cifra pareça desprezível, devemos considerar que, entre as 16 ocorrências do Jornal da Cultura, encontra-se a presença de um entrevistado, a cada dia da semana, que veio com o objetivo de explicitar facetas e enfoques possíveis para o caso Waldomiro Diniz e suas reverberações.

Assim, na segunda-feira, Heródoto Barbero fala com o deputado do PT, Cândido Vaccarezza, a favor da regulamentação dos bingos, pois, segundo ele eliminaria a questão da lavagem de dinheiro. Na terça-feira, Heródoto entrevista Luiz Fernando Delazari, que afirma a ligação entre os bingos, a máfia italiana e a lavagem de dinheiro. Este é a favor da cessação das atividades e aprova a MP (Medida Provisória) da proibição dos bingos. Na quarta-feira, Heródoto entrevista o senador Jorge Bornhausen, o qual acusa a polícia de não ter agilidade necessária e reforça a necessidade de uma CPI. Na quinta-feira, é a vez do jornalista Cláudio Tognolli, especialista em sigilos e vazamentos de informações. Ele manifesta a opinião de que há um exagerado uso do segredo na justiça brasileira. Na sexta-feira, Heródoto conversa com o senador Eduardo Suplicy, favorável à instalação da CPI para esclarecer o caso e até inocentar José Dirceu. Lembrou que Lula prometia o comparecimento de qualquer um dos seus ministros para esclarecimentos, o que estava acontecendo, e este procedimento também deveria aplicar-se a Dirceu.

Tal amostra é suficiente para expor um desenho constituído por diversas posições políticas e, conseqüentemente, diferentes enfoques para o caso explorado. A ela somam-se as notações de pesquisas de opinião pública, outra forma de explorarmos a diversidade de vozes.

É nestes termos que o Jornal da Record menciona a pesquisa DataFolha para mostrar que a maioria dos eleitores, $81 \%$, defende a CPI de Waldomiro Diniz; e o Jornal da Cultura indica pesquisa do Ibope, pela qual se revela que $68 \%$ dos brasileiros concordam que se divulguem informações dos processos.

Claro que as matérias voltadas para entrevistas não encerram a questão, pois todas as outras são pontilhadas por entrevistas na forma de pequenos depoimentos, em que políticos e pessoas do povo se manifestam. Mas aqui nos surpreendemos com o fato de que tanto o Jornal da Record quanto o Jornal da Cultura abriram espaço para testemunhos dos mais variados setores: da situação e da oposição, dos envolvidos com empresas lotéricas e dos implicados com as personagens centrais ao caso; enquanto o Jornal Nacional concentrou-se nos depoimentos de figuras do governo, dando assim maior ênfase às argumentações advindas do lugar que estava sendo posto em xeque. 
Essa explícita tomada de posição do Jornal Nacional é reforçada pela ausência de comentários críticos por parte de seus âncoras. Em nome da justeza, esta posição do jornal diz respeito a todos os envolvidos, acusados e acusadores. Se num primeiro momento podemos pensá-la como isenção, esta se vê neutralizada, uma vez que anteriormente se deu reforço à posição do governo. Ou seja, há uma opinião manifesta pelo veículo através do procedimento da escolha das vozes às quais ele concede a fala; existe uma opinião expressa na forma da omissão.

Onde há matérias pontuadas por comentário dos âncoras, devemos notar distinções quanto a sua natureza. O Jornal da Record, na figura de Boris Casoy, pratica uma constante vigilância sobre a ordem e por ela clama abertamente. Sobretudo, faz a cobrança da palavra, dada pelos políticos no passado, e a confronta com suas atitudes atuais. A freqüente formulação "Isto é uma vergonha" pontifica, reclama e exemplifica o modo de comentar. Já o Jornal da Cultura procura mostrar os diversos ângulos problemáticos da questão, para os quais os âncoras apontam sempre que oportuno. Heródoto, particularmente, volta e meia emite um juízo de valor, comparando ocorrências passadas, mas sem qualificar ou julgar o mérito da palavra dada.

Acreditamos que, nesta forma de procura da diversidade e manifestação de opinião que estamos acompanhando, é necessário incluir o papel das charges. Até nelas há diferenças de abordagem que marcam a possibilidade, pela crítica ou neutralidade, da apresentação de enfoques.

As charges de Chico Caruso, no Jornal Nacional durante o período de 2004, reforçam a idéia de que o governo tem um grande "abacaxi” nas mãos. Presidente e alto escalão são mostrados carregando abacaxis ou usando-os como capacete. Brincam com as vantagens econômicas de que Waldomiro usufrui, sem menção a sua ligação com o governo, ou melhor, sua posição nele.

Enquanto isso, Pegolli, chargista do Jornal da Cultura, faz uma crítica corrosiva aos políticos do governo e suas atitudes em face do escândalo Waldomiro. Há uma charge parodiando a entrega do Oscar, em que políticos recebem prêmios em categorias negativas; noutra, Lula comparece cantando com Gil "O Haiti é aqui..."; outra, ainda, em telefonema a Bush, mostra Lula afirmando que no Brasil não se quer descobrir nada; na seqüência, os políticos do governo aparecem discutindo soluções, cômicas, para abafar a CPI. Em charges, se a posição amena sinaliza uma anuência, certamente a posição crítica, para além da opinião manifesta, alude a enfoques diferenciados.

Iniciamos este texto afirmando que a constância do quadriculado e do quadrículo, constatável ao longo de três anos de observação, coloca os veículos estudados no ponto de aceitação implícita de uma divisão espacial constituinte de dispositivos disciplinares, propícios à emissão de palavras de ordem. Ora, tal ocorrência, pela repetição que implica, nos remete a fixações dos modos de ver o mundo e das relações de poder instituídas.

Contudo, ao examinarmos os modos de inserção dos veículos, um outro viés se insinua. A diversidade apresentada, sobretudo a diversidade das fontes, 
trabalha esgarçando os limites dos quadrículos, uma vez que coloca posições muitas vezes paradoxais. Estas não deixam de contestar, por implicação, a nitidez ou fixação do desenho do quadriculado. Não param de remeter às representações sociais, sempre na diversidade de perspectivas, e, com isso, desestruturar as identificações tão bem estabelecidas nessa equação do quadriculado.

Antes que tropecemos na tentação da apologia de um veículo em detrimento de outro, anotemos simplesmente este ponto em que o jornalismo rompe com o quadriculado instituído, quadriculado que cerceia os dizeres por meio da predisposição daquilo que deve ser dito, que barra a diversidade por conta de um notório efeito de homogeneização.

Neste ponto de desacordo, com o que se espera para cada quadrículo, é importante notar que as próprias táticas de fixação e supervisão, que lhes fazem suporte, podem estar a serviço de um outro olhar. Quando o jornalismo se empenha na realização de seu ideário, a saber, o exercício de confirmação e vigilância, ele atinge um ponto-limite em que se esgarça o quadriculado, pois uma situação antípoda se apresenta com a introdução de inúmeras vozes que colocam o fechamento, implicado pela homogeneização, em situação paradoxal.

Resumo: Este trabalho procura mostrar, por meio da observação de incidências temáticas e da diversidade de fontes, perfis de jornais televisivos. Emissões brasileiras, Jornal Nacional, Jornal da Record e Jornal da Cultura, são a base sobre a qual se desenvolveu este estudo.

Palavras-chaves: tópicos, jornalismo, perfil.
Abstract: This paper shows, as a result of observation on thematic incidence and source diversity, TV journalism profiles. Brazilian network, Jornal Nacional, Jornal da Record and Jornal da Cultura, are the ground for this study.

Keywords: topics, journalism, profile. 